\title{
El impacto social de la investigación en materia de vivienda. El caso de la cátedra Unesco de vivienda de la Universidad Rovira i Virgili ${ }^{1}$
}

\author{
Sergio Nasarre Aznar \\ Director Cátedra UNESCO de Vivienda \\ Universidad Rovira i Virgili \\ sergio.nasarre@urv.cat \\ Gemma Caballé Fabra \\ Cátedra UNESCO de Vivienda \\ Universidad Rovira i Virgili \\ gemma.caballe@urv.cat
}

Resumen: Nacida de la necesidad de devolver a la sociedad los resultados de una intensa investigación sobre derecho bipotecario y de la vivienda llevada a cabo desde hacía años, la Cátedra de Vivienda de la Universidad Rovira i Virgili nació como vehiculo funcional para transferir conocimientos y conseguir un impacto social real facilitando el acceso a la vivienda de las personas. Este artículo recoge las circunstancias que propiciaron el nacimiento de la Cátedra, única de Vivienda en el mundo reconocida por la UNESCO, y se analiza su cadena de valor que vincula investigación con docencia especializada, transferencia e impacto social, desvelando al mismo tiempo claves y ejemplificando su actividad e impacto con resultados.

Palabras clave: vivienda; impacto social; universidad; investigación; transferencia de conocimientos.

\footnotetext{
1 Este trabajo ha sido posible gracias al proyecto de investigación coordinado «Vivienda colaborativa» (DER2017-84726-C3-1-P) del Ministerio de Economía y Competitividad y a la concesión al Prof. Nasarre Aznar del premio ICREA Academia 2016-2020.
} 


\begin{abstract}
Born from a need to return to society the results of many years of intense research on mortgage and housing law, the University Rovira $i$ Virgili Housing Chair was created as a functional vebicle to transfer knowledge and to achieve a tangible social impact through facilitating access to housing. This article describes the circumstances that led to the establishment of the Chair, the only UNESCO Housing Chair in the world, and analyzes its value chain, which links research with specialized teaching, knowledge transfer and social impact. The article also presents key aspects of the Chair and provides examples of its activity and impact with specific results.
\end{abstract}

Key words: housing; social impact; university; research; transfer of knowledge. 


\section{Del porqué de las cátedras}

Cuando en una determinada organización existen estructuras y mecanismos funcionales para alcanzar todos sus objetivos, no es necesario crear más ${ }^{2}$. Y la universidad no es una excepción. Si las estructuras previstas en la Ley Orgánica 6/2001, de 21 de diciembre, de Universidades ${ }^{3}$ (en adelante, LOU), facilitasen eficientemente las cuatro tareas que debe desarrollar todo profesor universitario (docencia, investigación, transferencia y gestión ${ }^{4}$ ), no sería necesario crear otras adicionales.

De esta forma, por una parte, las rigideces de la docencia reglada universitaria (arts. 8 y 9 LOU) no favorecen diseñar grados (o, incluso, asignaturas) diferentes e innovadores, que a menudo son sustituidos por posgrados o cursillos en fundaciones o centros y academias de todo tipo. Por otra parte, en ocasiones, los departamentos (art. 9 LOU) no consiguen crear las condiciones para una investigación interdisciplinar con suficiente masa crítica e impacto internacional ${ }^{5}$, produciéndose demasiadas veces en su seno conflictos innatos a toda situación de escase $z^{6}$ y otros lamentables sucesos ${ }^{7}$; $y$ quedan solapados o sustituidos en sus funciones

2 La opción económica de «no hacer nada» (a menudo, la mejor, véase en <https://www.ft.com/content/ 511c6a84-8e36-11e7-a352-e46f43c5825d>, visitado: 27-04-2018) que da una explicación racional a este comportamiento. También en la sabiduría popular se encuentra la máxima empresarial «si algo funciona, no lo cambies».

3 BOE núm. 307, de 24 de diciembre de 2001.

4 Véanse los artículos 1 (Funciones de la Universidad), 2 (Autonomía universitaria), 33 (Función docente) y 39 (La investigación y la transferencia de conocimiento. Funciones de la universidad).

5 Cabe recordar que no hay ninguna universidad española entre las 200 mejores del mundo en 2017 (véase en <https://www.elespanol.com/reportajes/20170814/238976666_0.html>, visitado: 06-04-2018).

6 Véase la reflexión que hace Viglizzo (2001:34) en relación a la competencia y la escasez de recursos.

7 Últimamente han trascendido a los medios de comunicación algunos de ellos, incluso con políticos beneficiados como, por ejemplo: a) la presumiblemente poco aprovechada beca de investigación del político de Podemos Íñigo Errejón (<http://www.libertaddigital.com/espana/2016-06-07/archivada-la-causa-contra-errejon-por-su-contrato-en-la-universidad-de-malaga-1276575804/>, visitado: 06-04-2018); b) la supuesta tesis plagiada por el que fue presidente de la Comunidad Valenciana Francisco Camps (<http://www.elmundo.es/comunidad-valenciana/2016/10/04/57f39056468aeb6a0a8b4613.html>, visitado: 06-04-2018); c) el supuesto máster en la Universidad Rey Juan Carlos de la ya dimitida presidenta de la Comunidad de Madrid, Cristina Cifuentes (<https://www.elconfidencial.com/espana/2018-04-06/cristina-cifuentes-master-rector-universidad-acta_1545398/?utm_source=facebook\&utm_medium=social\&utm_campaign=ECDiarioManual>, visitado: 27-4-2018). Aunque también aparecen en prensa asuntos académicos relacionados con no políticos, como asuntos de plagio (<http://www.elmundo.es/madrid/2017/02/09/589b83e12260 1d50468b461f.html>, visitado: 06-04-2018); sobre nepotismo (<https://www.elconfidencial.com/amp/ espana/2018-04-15/nepotismo-universidad-oviedo-geologia_1550116/?utm_source =twitter\&utm_medi$\mathrm{um}=$ social\&utm_campaign=ECFDManual\&_twitter_impression=true $>$, visitado: 16-04-2018); o sobre endogamia mal entendida (ver <http://www.elmundo.es/espana/2018/04/23/5adcc0ea268e3eaa7f8b45f7. html $>$, visitado: 24-04-2018). En este contexto, tampoco es de extrañar el pico en 2016 de presentaciones de tesis doctorales elaboradas y defendidas en tiempo récord por cambio de normativa, con un elevadísimo número de máximas calificaciones (el 93,8\%, por ejemplo, en la Carlos III) (<http://www.elmundo.es/sociedad/2016/03/08/56dc6d7546163ffd4c8b45aa.html>, visitado: 06-04-2018). Ni tampoco, pues, es de extrañar que se publiquen libros turbo pretendidamente científicos de cientos de páginas que cuentan para sexenios o plazas sin una sola cita que contraste lo que se está opinando o afirmando. 
por grupos de investigación, centros de investigación e institutos de investigación (art. 10 LOU), que, fuera de las universidades, ya se llevan en 2018 más financiación que estas ${ }^{8}$ (¿quizá porque sus miembros pueden dedicarse exclusivamente a la investigación?). A ello cabe añadir, en cuanto a la gobernanza de centros, departamentos y de las universidades, que son puestos a los que se accede por un sistema de elección entre sus miembros — arts. 13, 18 y 19 LOU - en el que no se tienen en cuenta necesariamente ni el mérito ni la capacidad ni el haber demostrado excelencia en investigación, docencia y/o transferencia ${ }^{9}$. En este sentido, en toda esta estructura subsiste la duda de si realmente queda un espacio para la transferencia de la investigación a la sociedad (¿lo lleva real y efectivamente a cabo el Consejo Social conforme al art. 14 LOU?), a pesar de que es función de la universidad estar al servicio de esta (conforme a los arts. 1.3, 39, 41.2 y 93 LOU).

Y, finalmente, en cuanto al «impacto social», en la exposición de motivos de la LOU se dice que «la Ley realza la importancia presente, y sobre todo futura, que la investigación tiene como factor diferenciador y de calidad en el desarrollo competitivo de la Universidad, y reconoce, al mismo tiempo, el impacto positivo de la actividad científica en la sociedad, en la mejora de la calidad de vida de los ciudadanos y en la creación de riqueza». Por su parte, el art. 27.1 de la Declaración Universal de los Derechos Humanos (DUDH) preceptúa que «toda persona tiene derecho a tomar parte libremente en la vida cultural de la comunidad, a gozar de las artes y a participar en el progreso científico y en los beneficios que de él resulten»; es decir, preconiza un derecho de las personas a participar de los beneficios del progreso científico y tecnológico. Para alcanzar esta finalidad, tiene un papel relevante a desarrollar la transferencia de conocimientos, cuya cuantificación y calidad deberían ir vinculadas al impacto social real conseguido, orientando con ello las políticas públicas en investigación, que tendrían que promocionar aquellas investigaciones efectivamente transferidas y que realmente impacten en el bienestar y progreso de la generalidad (Sánchez Barrilao, 2017:347).

8 Así ha sucedido ya, al menos, en la problemática resolución provisional de la convocatoria de ayudas a Grupos de Investigación de Cataluña (Resolución EMC/1164/2017, de 24 de mayo, DOGC núm. 7379 de 29-52017). Ver <https://www.elperiodico.cat/ca/ciencia/20180415/ciencia-universitats-catalanes-llanca-sos-financament-sgr-6728284> (visitado: 16-04-2018).

9 Otra opción es que lo sean profesionales de la gestión — docentes o no- contratados especialmente por el claustro de profesores para hacer a la universidad, su facultad o departamento más competitivos frente a los de otras universidades, con una buena política de objetivos, promociones, contrataciones, plan pedagógico, etc., como sucede habitualmente en universidades anglosajonas. Ver el perfil de la contratación de decanos en Reino Unido y en Estados Unidos en <http://www.jobs.ac.uk/careers-advice/job-profiles/1771/dean> (visitado: 05-04-2018). Un ejemplo de oferta el 05-04-2018 es el de decano para la School of Health and Life Sicences en la Glasgow Caledonian University en <http://www.jobs.ac.uk/job/BIN211/dean-school-of-health-andlife-sciences/> (visitado: 27-04-2018), donde requieren que la persona que sea contratada para el puesto «will have ultimate responsibility to drive school performance and its quality across standards for teaching, research and knowledge transfer». 
De ahí que el impacto social que pueda tener un proyecto europeo sea uno de los aspectos clave para tener en cuenta a la hora de decidir sobre la financiación o no de este por parte de las instituciones de la Unión, teniendo en cuenta también las prioridades u objetivos a alcanzar por parte de esta ${ }^{10}$. Sin embargo, el impacto social de las ciencias sociales y humanidades ha sido cuestionado por la Unión Europea argumentando que no existen evidencias claras sobre el impacto social y político de la investigación en este ámbito ${ }^{11}$.

En el Reino Unido existe una base de datos específica (The Research Excellence Framework ${ }^{12}$ ) para evaluar el impacto social de los proyectos y sirve como un indicador más para decidir sobre la financiación de las universidades. En esta línea, a nivel internacional también se ha creado recientemente el repositorio SIOR ${ }^{13}$ (Social Impact Open Repository), que tiene como objetivo identificar las vías de evaluación del impacto de las ciencias sociales y las humanidades.

Pues bien, es en este contexto donde surge la Cátedra de Vivienda de la Universidad Rovira i Virgili ${ }^{14}$, objeto de especial análisis en este artículo y que, aunque sin amparo explícito en la $\mathrm{LOU}^{15}$, sí lo tiene en el art. 136 del Estatuto de dicha universidad ${ }^{16}$, posiblemente basado en el art. 26 de la ley catalana de universidades (en adelante, LUC ${ }^{17}$ ) y en el marco del art. 27 DUDH.

Así, el art. 136 del Estatuto de la Universidad Rovira i Virgili señala aséptica y algo difusamente ${ }^{18}$ que «la Universidad puede concertar la creación de foros de colaboración y difusión de sus actividades de investigación y formación especializada con entidades públicas o privadas bajo la fórmula de cátedras que

10 Véanse las 10 prioridades de la Comisión de la Unión Europea para 2015-2019 en: <https://ec.europa.eu/ commission/priorities_es > (visitado: 25-04-2018).

11 La presión de más de 25.000 investigadoras e investigadores provocó que el Parlamento Europeo incluyera un challenge en Horizon 2020 dedicado a las ciencias sociales y humanidades. Sin embargo, la financiación de las ciencias sociales continúa estando amenazada. Véase con más profundidad Flecha García (2015: 65).

12 Véase esta base de datos en: <http://impact.ref.ac.uk/CaseStudies/search1.aspx> (visitado: 25-04-2018). 13 Véase este repositorio en: <http://sior.ub.edu/jspui/> (visitado 25-04-2018). El SIOR es un repositorio de acceso abierto para mostrar, compartir y almacenar el impacto social de los resultados de la investigación y ha sido impulsado por el proyecto «IMPACT-EV» (<https://impact-ev.eu>, visitado: 25-04-2018).

14 No confundir las cátedras como estructuras con los «catedráticos de universidad» como profesorado universitario funcionario (art. $56 \mathrm{LOU}$ ) o los profesores contratados permanentes llamados también «catedráticos» del art. 44 LUC.

$15 \mathrm{El}$ art. 2.3 LOU vincula la actividad de la universidad con la libertad académica que se manifiesta en la de cátedra, investigación y estudio, pero nada dice sobre la transferencia para promover un cambio en la sociedad; contrástese con el art. 26 LUC y el art. 136 Estatuto URV que comentamos infra.

16 BOE núm. 107, 4-5-2012, pp. 33587 y ss.

17 Ley 1/2003, de 19 de febrero, BOE núm. 60, 11-3-2003.

18 Este artículo está hoy desarrollado por el Reglamento para la creación y el funcionamiento de las Cátedras URV, versión vigente desde 22-12-2014, disponible en < http://www.urv.cat/media/upload/arxius/catedres/ reglament-catedres-2014.pdf> (visita 6-4-2018), que también otorga un amplio margen de funciones y finalidades a estas estructuras. Puede hallarse el listado de las cátedras existentes en la URV y sus actividades en <http://www.urv.cat/ca/societat-empresa/catedres/> (visita 6-4-2018). 
lleven el nombre que se convenga o el mismo de la entidad». Es decir, permite la creación de unas estructuras adicionales a las ya existentes. Les llama «foros», pero el art. 26 LUC preceptúa que «el departamento competente en materia de universidades y las universidades públicas deben adoptar las medidas pertinentes para impulsar la transferencia de tecnología y la transmisión de conocimientos a la sociedad. Con esta finalidad, las universidades pueden crear y promover entidades, centros y estructuras ${ }^{19}{ }$. Estas han de servir para «colaborar»y «difundir» sus «actividades de investigación y formación especializada». Y se concierta su creación «con entidades públicas o privadas». En el preámbulo de la LUC se establece que «se considera la universidad como motor de la economía, mediante el estímulo a la innovación. En este sentido, hay que destacar la importancia de la colaboración entre las universidades y las empresas para la transferencia de conocimientos y la tecnología».

Visto esto, a nuestro juicio las cátedras nacen para que la universidad pueda colaborar con otras entidades públicas o privadas, con las que desarrollar y difundir investigación y formación especializadas. $\mathrm{O}$ sea, allí donde no llegan los grados y posgrados oficiales ( $y$ tradicionales, por lo complicado de innovar ${ }^{20}$ ), allí donde no llega la investigación dedicada a temas tradicionales, con acciones meramente individuales sin suficiente masa crítica, y dado que ningún órgano de la universidad se preocupa especialmente ni de la transferencia ni del impacto social de la investigación, allí deben llegar las cátedras apoyadas científica y económicamente por terceras instituciones del entramado económico-social. Llegar a concebir este órgano e impulsar luego su desarrollo no es sencillo, y se necesitan unos responsables universitarios con clara vocación universitaria y que apuesten por que la ciencia esté orientada a conseguir un auténtico impacto social ${ }^{21}$.

19 La cursiva es añadida por los autores de este artículo.

$20 \mathrm{El}$ proceso de elaboración de los planes de estudio, así como sus cambios, iniciación de nuevos grados, etc., es complejo y largo, no facilita ni agiliza la innovación y el desarrollo. Véase el proceso en los arts. 35 LOU y 104 a 114 LUC.

21 Grau Vidal (2012: 3) enfatiza la importancia que tienen las universidades no solo en cuanto a su función educativa en el nivel superior, sino también en la generación de conocimiento y en su transformación en valores culturales, sociales y económicos. La URV, pese a su juventud — recientemente ha celebrado sus 25 años de vida—, se ha posicionado muy bien en ránquines nacionales e internacionales (ver <http://www.urv.cat/es/ universidad/conocer/presentacion/rankings/>, visitado: 24-04-2018). La juventud y el dinamismo de su profesorado, libre del anquilosamiento propio de universidades seculares de mayores dimensiones y del desarrollo científico y organización tradicionales, ha posibilitado este extraordinario desarrollo. No obstante, ya en 2018, se está enfrentando a un inminente recambio generacional, lo que representa todo un reto en relación a la promoción de investigadores jóvenes. 


\section{Origen y evolución de la Cátedra de Vivienda de la Universidad Rovira i Virgili}

La Cátedra de Vivienda de la Universidad Rovira i Virgili (URV ${ }^{22}$ ) fue creada el 11 de julio de 2013 por el Consejo de Gobierno de esta universidad. Su objetivo fundacional, conforme al art. 136 del Estatuto de la universidad, es la creación de una plataforma estable en investigación, docencia y transferencia de conocimientos especializada en temas de vivienda, tanto a nivel nacional como internacional.

Sin embargo, este no fue realmente el inicio de la actividad investigadora en materia de vivienda en la universidad, dado que la Cátedra es el fruto de la investigación y de los proyectos sobre vivienda que se venían llevando a cabo en este ámbito desde el año 1996 por diversos investigadores, hoy integrados en la Cátedra ${ }^{23}$, y que generaron en su momento el Grupo de Investigación de Acceso a la Vivienda (Housing Research Group) de la Universidad Rovira i Virgili24, que, aunque informal (las circunstancias así lo aconsejaban), funcionaba de facto.

En este sentido, la necesidad de la estructuración de la investigación sobre vivienda y de aunar esfuerzos a través de una cátedra sobre esta temática —ausente prácticamente en todo el panorama universitario español, excepto la creación un año antes de la Cátedra Zaragoza Vivienda ${ }^{25}$ - surgió como reacción académica a las consecuencias socioeconómicas que nos ha deparado - y aún nos depararála crisis económica iniciada en 2007 (Nasarre Aznar, 2014: 37), pues la vivienda no es un bien cualquiera: es el único bien que al mismo tiempo es un importante activo económico y financiero y un derecho humano (Nasarre Aznar, 2017: 45). Precisamente, las consecuencias de la crisis evidenciaron las debilidades del sector de la vivienda y de su marco legal, no solo en España, sino también en gran parte del ámbito europeo e internacional, así como también los retos que se tenían que afrontar en el futuro para evitar otra burbuja inmobiliaria y, en definitiva, no repetir los mismos errores que contribuyeron a crear la crisis o a agravarla. De hecho, Pilar Martínez, entonces directora general de Arquitectura, Vivienda y Suelo del Ministerio de Fomento, en la presentación pública de la Cátedra, en 2014, afirmó: «Si [la Cátedra] hubiera existido años antes de la crisis de 2007, posiblemente la hubiéramos podido prever o reducir sus consecuencias».

También hubo motivos más prosaicos para crear la Cátedra: la necesidad de romper los corsés clásicos - y más en derecho- de la división de la ciencia por áreas estancas (verdadero impedimento para hacer una investigación interdis-

22 Véase <http://housing.urv.cat/es/> (visitado: 06-04-2018).

23 Véase <http://housing.urv.cat/es/portada/presentacion/investigadors/> (visitado: 06-04-2018).

24 Véase <http://housing.urv.cat/es/portada/investigacion/housing-research-group/> (visitado: 06-04-2018). 25 Véase <https://catedrazaragozavivienda.wordpress.com> (visitado: 06-04-2018). 
ciplinar, como es la vivienda) enraizadas en sus ECTS de docencia (de los que penden las plazas del profesorado); la disfuncionalidad de algunos departamentos para convertirse realmente en entidades que promuevan una investigación interdisciplinar con impacto internacional y suficiente masa crítica; y, en definitiva, la necesidad de sus promotores de «abandonar el nido» ya con madurez científica $y$ «salir de la zona de confort ${ }^{26} »$ a la búsqueda de nuevas fronteras y horizontes científicos, lo que implicaba, en definitiva, apostar por proyectos de investigación propios sin generar una grieta en el statu quo.

Las cátedras, tal y como están concebidas en el Estatuto de la URV, son un instrumento ideal para dar el primer paso en este sentido, puesto que permiten la interdisciplinariedad que requiere el análisis de la vivienda y la implicación de terceros stakeholders, sin que ello provoque cambios traumáticos ni en el departamento ni en el grupo de investigación, ni, en su caso, en la composición de los proyectos de investigación.

Si el gobierno de una universidad comprende todo esto, se tiene ya el primer elemento para organizar una cátedra. Para lograrlo, es necesario mostrarles a los altos responsables académicos que lo que se propone hacer es algo especial, diferente, que puede ayudar a las personas - lo que, a nuestro juicio, debe ser el leitmotiv de toda universidad pública- y que uno es capaz de hacerlo. En el caso de la Cátedra de Vivienda de la URV, la promoción para su creación se hizo coincidir con uno de los mayores congresos organizados en la Facultad de Ciencias Jurídicas de dicha universidad desde 1992, el 25. congreso de la European Network for Housing Research (ENHR), donde se presentaron casi 500 papers y participaron investigadores de 40 países en $2013^{27}$. Esta finalidad de ayudar a las personas y la posibilidad real de generar cambios de calado es el banderín de enganche para los stakeholders.

El segundo elemento consiste en buscar partners privados, requeridos por la reglamentación de las cátedras, con lógica: ¿qué investigación, docencia, transferencia o impacto eficaces se pueden hacer si ningún stakeholder relevante confía en lo que uno hace o propone y en lo que puede ofrecer? Es, pues, necesaria su implicación en el sustento económico de toda nueva cátedra. Pero entendemos que debe haber un límite: como universidad pública, los intereses privados no pueden condicionar la investigación pública; aunque sí pueden contribuir a ella. Para ello, debían cumplirse dos tipos de requisitos. Primero, requisitos objetivos: necesidad de varios partners (y no solo uno grande) que aporten cantidades monetarias limitadas en su cuantía y que la cátedra realmente se financie por vías competitivas

26 Igual habrán oído la expresión «se pasa mucho frío fuera del grupo de investigación».

27 Véase <http://www.lavanguardia.com/local/tarragona/20130620/54376140923/la-urv-tindra-una-catedra-d-habitatge-pionera-a-l-estat-a-partir-de-l-any-que-ve.html> (visitado 27-04-2018). 
(para asegurar la calidad y el interés de la temática tratada), por ejemplo, a través de proyectos de investigación o de transferencia en los que estos puedan participar. Y, segundo, un elemento subjetivo: las instituciones que quieran participar deben ser conscientes de que los resultados de la investigación a veces serán de su agrado o serán conformes a sus intereses corporativos y de lobby y, a veces, no.

Siguiendo escrupulosamente estos parámetros, en el caso de la Cátedra de Vivienda de la URV se pudieron reunir nueve entidades públicas y privadas locales (la primera, la Cámara de la Propiedad Urbana de Tarragona, hoy seguida por el Consell de Cambres de la Propietat Urbana de Catalunya; el Ayuntamiento de Tarragona -SMAHUSA — ; el Ayuntamiento de Reus; el Colegio de Agentes de la Propiedad Inmobiliaria de Tarragona y el Colegio de Administradores de Fincas de Tarragona), de la comunidad autónoma (Agencia de la Vivienda de Cataluña, el Decanato en Cataluña del Colegio de Registradores de la Propiedad y Mercantiles, el Colegio de Notarios de Cataluña) y a nivel nacional (Consejo General de Agentes de la Propiedad Inmobiliaria y Consejo General de Administradores de Fincas de España). Los partners se irían convirtiendo, poco a poco, en imprescindibles compañeros de viaje de la Cátedra, tanto para transferencia como para proyectos y para, en última instancia, conseguir impacto social con nuestra investigación.

Y el tercer elemento lo constituyen investigadores noveles que se ilusionasen con el proyecto, puesto que de poco sirve intentar consolidar una línea de investigación novedosa si no hay nadie a quien formar, que poco a poco vaya aportando ideas, vías y métodos frescos propios de la juventud. En un momento en que los de la generación $\mathrm{X}^{28}$ ven con cierto escepticismo la irrupción de los millennials ${ }^{29}$ en nuestras clases y en los ámbitos social y profesional (también en la investigación científica), estos tienen un rol destacado y activo a desempeñar en la investigación relacionada con las dificultades de acceso a la vivienda, nuevas tecnologías, vivienda colaborativa, etc. Hoy la Cátedra de Vivienda de la URV cuenta con un extraordinario equipo de jóvenes investigadoras, unas que ya han acabado sus tesis y otras que están en ello ${ }^{30}$.

La figura 1 resume los elementos que han sido necesarios para la forja de la Cátedra.

\section{Figura 1. Condicionantes para la creación de la Cátedra de Vivienda URV.}

28 Las personas nacidas aproximadamente a mediados de los años sesenta hasta mediados de los ochenta.

29 Las personas nacidas aproximadamente a partir de los noventa. Ver la discusión en <http://www.elmundo. es/papel/historias/2018/04/26/5adf54baca4741ce088b4627.html> (visitado: 28-04-2018).

30 Véase en: <http://housing.urv.cat/portada/presentacio/investigadors/> (visitado: 26-04-2018). 


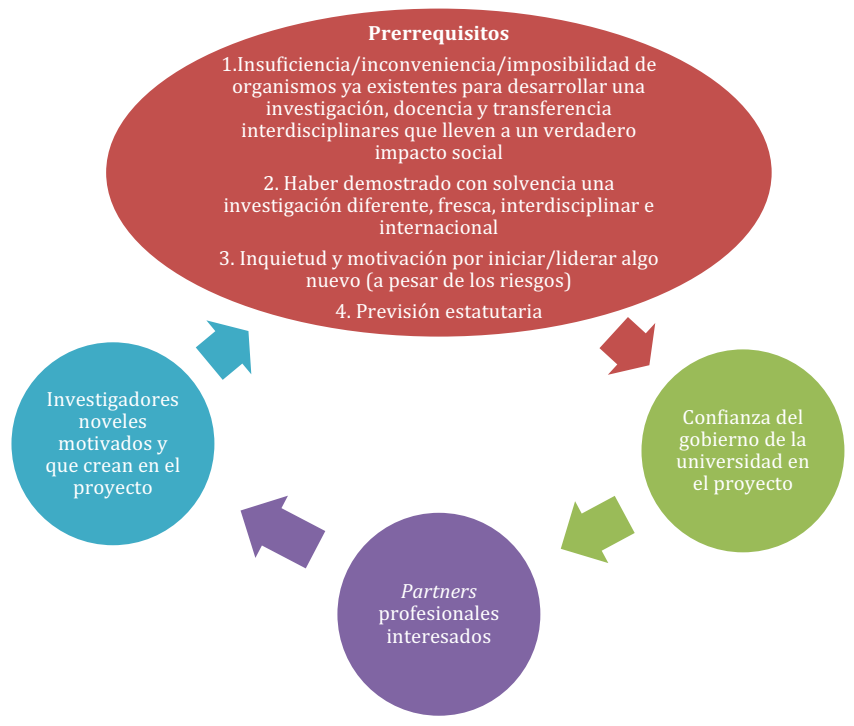

Fuente: elaboración propia.

Y todo esfuerzo tiene su recompensa. En 2016 la investigación de la Cátedra fue reconocida con el premio ICREA Academia 2016-202031. En 2017 la Cátedra fue reconocida por la UNESCO (United Nations Educational, Scientific and Cultural Organization) como la sede de la primera cátedra del derecho a la vivienda del mundo ${ }^{32}$. En 2018 se han culminado con éxito 13 proyectos nacionales e internacionales, se han defendido 4 tesis doctorales ( 3 de ellas internacionales), en 4 años se han publicado 117 trabajos científicos en 9 países, se ha impulsado un posgrado homologado en mediación y un curso homologado para ser agente inmobiliario acreditado, se ha contribuido a elaborar 5 leyes, se han impartido 212 conferencias en 26 países, se han organizado 20 workshops interdisciplinares e internacionales, se han producido un documental y una experiencia de simulación para jóvenes sobre sinhogarismo ${ }^{33}$, se publica semestralmente una revista (Housing) y se ha impactado en 5,7 millones de oyentes, 3,6 millones de telespectadores y 48,3 millones de lectores ${ }^{34}$.

31 Véase en: <https://www.icrea.cat/en/icrea-academia-awardees> (visitado: 26-04-2018).

32 Véase en: <https://en.unesco.org/sites/default/files/list-unesco-chairs.pdf> (visitado: 26-04-2018).

33 Sobre el documental, véase en <http://catalanfilms.cat/ca/produccions/El-umbral> (visitado: 26-042018) y en <http://housing.urv.cat/es/documental-el-umbral/> (visitado: 01-08-2018). Sobre la experiencia de simulación, ver http://housing.urv.cat/es/experiencia-el-llindar/ (visitado: 01-08-2018).

34 En relación con el número de leyes donde se ha colaborado, las conferencias realizadas, los workshops, las publicaciones..., desde la Cátedra se lleva una cuantificación de todas las actividades, trabajos y actos donde participa, de esta manera nos permite conocer la producción científica y las actividades de divulgación o transferencia. Las memorias de la Cátedra pueden consultarse y descargarse en <http://housing.urv.cat/es/porta$\mathrm{da} /$ presentacion/memoria/> (visitado: 01-08-2018). En cuanto al número de los oyentes, telespectadores y 
Con esta actividad, la estructura de la Cátedra se va volviendo más compleja. Hoy (2018), el equipo humano que conforma la Cátedra tiene carácter interdisciplinar y lo conforman 5 investigadoras júnior o predoctorales y 14 investigadores/as sénior, provenientes de disciplinas como el derecho y el trabajo social. La figura 2 muestra su estructura en 2018.

Además, debe tenerse en cuenta que la Cátedra es un órgano de la universidad. De ella cabe destacar: que la actividad de la Cátedra descansa sobre la investigación desarrollada por el Housing Research Group ${ }^{35}$; que la Cátedra goza de una comisión asesora interdisciplinar formada por investigadores y prácticos consolidados en el ámbito de la vivienda con los que se reúne formalmente una vez al año (junto con la comisión de seguimiento) pero que se coincide con ellos con regularidad en los diversos eventos científicos; también cuenta con una comisión de seguimiento de la que forman parte nativamente todos los partners de la Cátedra; y con un consejo de investigación, en el que participan los séniors de la Cátedra. De transferencia y de investigación penden los proyectos y su proyección internacional. Así, investigadores internacionales llevan a cabo estancias de investigación (de una semana a un año) con las que se intercambian conocimientos y experiencias. Hasta el momento han realizado estancias de investigación en la Cátedra profesores de Chile, Sudáfrica, Irlanda, Malta, Luxemburgo, Italia, Polonia, Alemania e Israel.

Finalmente, cabe añadir que desde su fundación se consideró prioritario que la Cátedra se dotara de una oficina técnica propia (para llevar de la agenda común de los miembros, gestión de proyectos, de viajes, de los contratos de los investigadores, follow up de las gestiones internas de la universidad y externas a esta, gestión investigadores visitantes, base de datos, página web, edición de la revista, etc. ${ }^{36}$ ) y de tres servicios transversales también propios que debían funcionar como un engranaje: servicio de comunicación (medios de comunicación y redes sociales), informática (apoyo, diseño y actualizaciones técnicas de páginas web) y revisión y, en su caso, traducción de textos (p. ej, artículos científicos, propuestas de proyectos) en inglés.

\footnotetext{
lectores, los contabiliza periódicamente una empresa especializada en investigación social y de mercados externa a la universidad (<http://santiariste.com/ca/>, visitado: 01-08-2018). También la URV tiene un servicio de pressclipping; ver, por ejemplo, el número de lectores y el impacto económico de un breve aparecido el 0407-2018 en la prensa local en <https://www.pressclipping.com/sp3/redir.php?485-01-KgnjJNxXKwu9N1HPEmbJCWg-423-10469-0-7192518-2060-NA> (visitado: 01-08-2018).

$35 \mathrm{Ver}<$ http://housing.urv.cat/es/portada/investigacion/housing-research-group/> (visitado: 28-04-2018). 36 De lo contrario, todo esto seguiría recayendo sobre los investigadores, lo que lastraría el desempeño de las tareas que les son propias.
} 
La figura 2 muestra ${ }^{37}$ la estructura organizativa de la Cátedra con la distribución de responsabilidades y tareas entre sus miembros en función de la temática. Por ejemplo, existe un responsable proyectos de investigación, de la transferencia de conocimientos (tanto de recibir las propuestas de transferencia como el ser proactivo ofreciéndolas a la sociedad), unos responsables de docencia especializada que son los directores de los dos posgrados y una responsable de controlar el impacto social de la investigación (tanto ex ante en la elaboración de los proyectos como ex post, haciendo el follow up de los mismos y hallando indicios del impacto) y responsables para cada subárea.

\section{Figura 2. Estructura organizativa de la Cátedra UNESCO de Vivienda URV en 2018.}

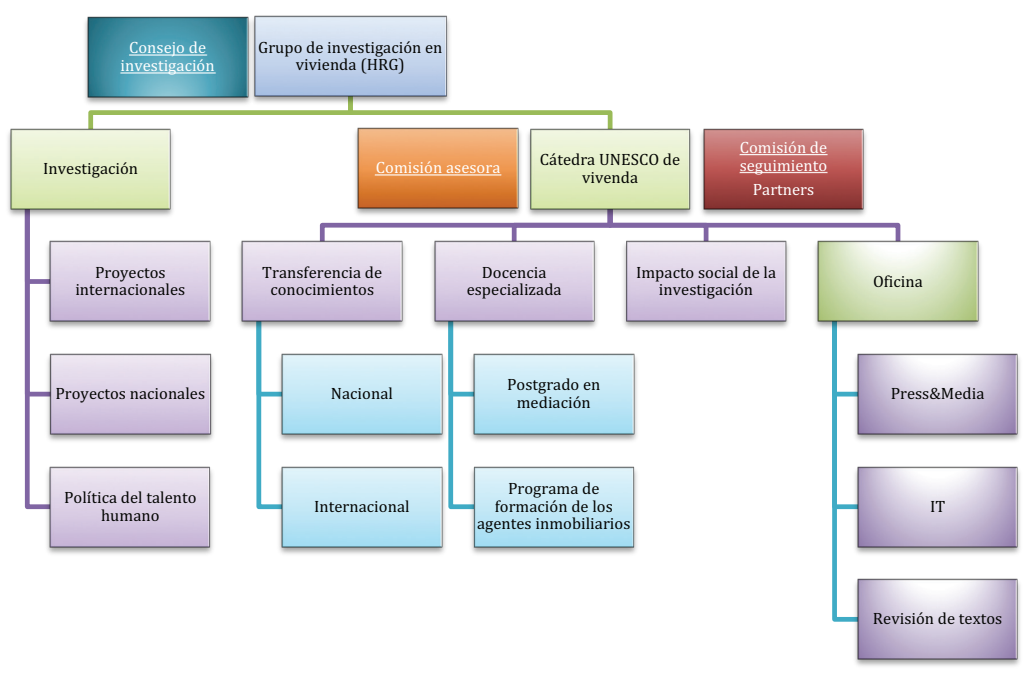

Fuente: elaboración propia.

37 Véase con más profundidad la estructura y organización de la Cátedra en <http://housing.urv.cat/es/portada/investigacion/housing-research-group/> (visitado: 01-08-2018). 


\section{La actividad de la Cátedra. De la investigación al impacto social}

\subsection{La investigación como base del impacto social}

Sin investigación, nada se puede explicar, nada se puede transferir ni ningún impacto positivo en la sociedad se puede generar que tenga cierta base sólida (Payne-Gifford, 2014: 16), especialmente en una temática tan compleja como es la vivienda, que a menudo es objeto de maniqueísmos interesados y de sencillas recetas.

La figura 3 resume la actividad de la Cátedra. De ella se desprende que la investigación se sitúa en el origen para poder llevar a cabo, posteriormente, el resto de las actividades, es decir, la transferencia de conocimientos, la docencia especializada y conseguir ulteriormente impacto social.

Figura 3. La actividad de la Cátedra UNESCO de Vivienda.

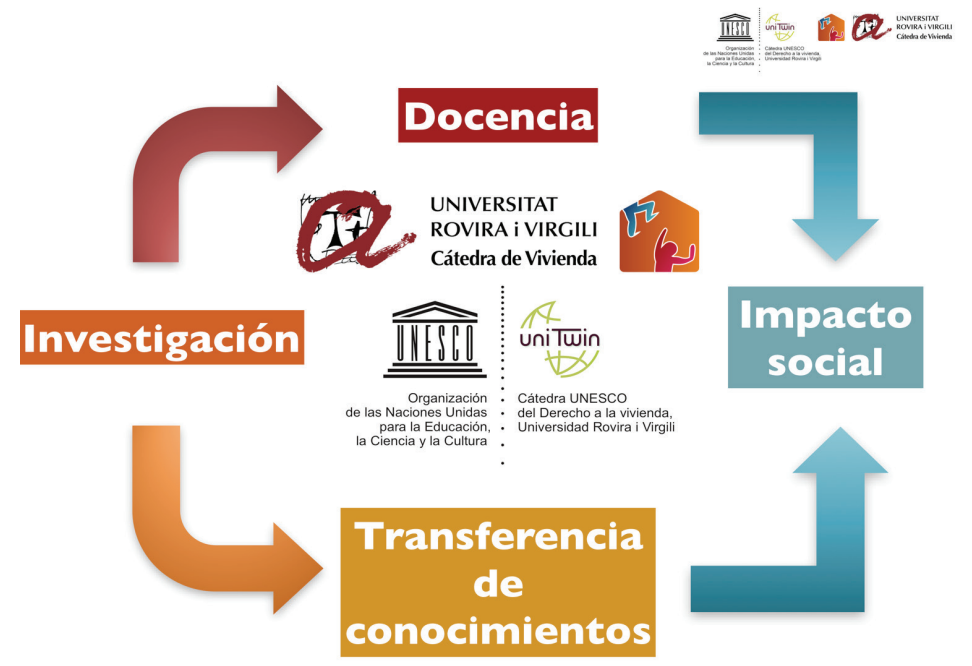

Fuente: elaboración propia.

1. La investigación. La investigación especializada en vivienda está en el origen y en el corazón de la Cátedra y formalmente corre a cargo del Grupo de Investigación sobre Vivienda (Housing Research Group), que nació en 2009 como un mero logo y página web, pero en el que diversos investigadores/as se sentían cómodos/as hasta que se refundó oficialmente en 2017 (ver figura 2 supra). La investigación generada en la Cátedra se sustenta sobre los siguientes cuatro pilares temáticos: 
a) La vivienda como derecho humano. Y dentro de él, los desahucios, el sinhogarismo, el derecho a la ciudad, la prevención del sobreendeudamiento y la protección de consumidores.

b) El acceso a la vivienda. En este pilar se incluyen la vivienda colaborativa, los arrendamientos urbanos, la rehabilitación por renta, las tenencias intermedias y el derecho hipotecario.

c) La gestión y la organización de la vivienda. Y dentro de él, la intermediación inmobiliaria, la gestión de la vivienda social, tributación de la vivienda, los «condohoteles», la accesibilidad, la eficiencia energética y el «proptech ${ }^{38} »+$

d) La vivienda como activo financiero, que cubre la hipoteca inversa y el mercado hipotecario.

La mayoría de los temas de investigación de la Cátedra que se incluyen en cada uno de estos pilares están o han sido financiados con proyectos de investigación de carácter tanto nacional como internacional. Algunos ejemplos de los segundos son «TENLAW" ${ }^{39}$ »; «Promoting protection of the right to housing - Homelessness prevention in the context of evictions ${ }^{40} »$; «The cross-border acquisition of real estate in EU: problems which arise for citizens ${ }^{41} » ; \mathrm{y}$ «From sharing to caring: examining socio-technical aspects of the collaborative economy ${ }^{42} »$.

Pero una particularidad relevante del trabajo llevado a cabo en la Cátedra es que la investigación no sigue un estudio descriptivo de una determinada situación, ley, sentencia o institución, sino que busca innovar, proponer soluciones o medidas para mejorar o cambiar una realidad y la vida de las personas. Se huye conscientemente de trabajos meramente descriptivos, tan comunes en nuestra academia y en la investigación en derecho ${ }^{43}$.

38 El término proptech (propiedad y tecnología) es el resultado de la combinación del sector inmobiliario y el de la tecnología. Véase en: <http://proptech.es> (visitado: 03-05-2018).

$39<$ http://www.tenlaw.uni-bremen.de> (visitado: 25-04-2018).

$40<$ http://ec,europa.eu/social/main.jsp?catId=738\&langId=en \&pubId=7892\&type=2\&furtherPubs=y es $>$ (visitado: 21-04-2018).

41 <http://www.europarl.europa.eu/RegData/etudes/STUD/2016/556936/IPOL_STU(2016)556936_ EN.pdf> (visitado: 21-04-2018).

42 <http://housing.urv.cat/seminari-internacional-socio-technical-aspects-of-the-circular-and-collaborativeeconomy/> (visitado: 27-04-2018).

43 De conformidad con Gurrea Martínez (2018: 5), «en España, Portugal y América Latina, a modo de ejemplo, los investigadores de Derecho, por lo general, suelen realizar trabajos meramente descriptivos o interpretativos de las opiniones o textos legales vigentes. Y aunque estos trabajos aporten valor a la sociedad (por ejemplo, facilitando el conocimiento e interpretación de las leyes a estudiantes y operadores jurídicos), no contribuyen a lo que, a nuestro modo de ver, es la función social de los investigadores». Nótese que ello puede derivar en un lucrativo negocio, como el publicado recientemente en la UNED de 20 millones de euros (<https:// www.elconfidencial.com/espana/2018-04-24/negocio-cautivo-manuales-uned-mercado-20millones-catedraticos_1552934/>, visitado: 24-04-2018). 
De hecho, si se alcanza esta mejora propuesta en la investigación, es cuando se puede hablar propiamente de impacto social de la misma, que más adelante se explica. De hecho, tal es (o debería ser) la función última del investigador ${ }^{44}$, por lo menos, del público.

2. La docencia. La Cátedra organiza una docencia especializada, basada en la investigación que realiza y destinada tanto a los profesionales del mercado inmobiliario y de la vivienda como a los trabajadores de las Administraciones públicas y responsables políticos, así como también a los ciudadanos en general. En este sentido, desde la Cátedra se ofrece el Curso de Agente Inmobiliario ${ }^{45}$, reconocido por la Generalitat de Cataluña, que habilita a los que lo superen a inscribirse en el Registro de Agentes Inmobiliarios; y también un Posgrado de Mediación ${ }^{46}$ que habilita a sus titulados a acceder a los registros oficiales de mediadores. Además, los investigadores de la Cátedra también imparten docencia en el Grado de Derecho, el Máster de Acceso a la Abogacía y el Máster en Derecho de la Empresa y la Contratación de la Universidad Rovira i Virgili, entre otros grados y cursos, siempre aportando información y llevando a cabo actividades pedagógicas relacionadas con el derecho de la vivienda.

3. La transferencia de conocimientos. Los resultados o conclusiones de la investigación no solo se quedan en publicaciones académicas ${ }^{47}$ o en la docencia que se imparte sino que, además, se divulgan a través de los distintos congresos, workshops, y otras actividades que la Cátedra organiza o en los que participa. A ello cabe añadir que cada año desde 2015 la Cátedra organiza un curso de verano itinerante (en un municipio distinto cada año) ofrecido por la Universidad Rovira i Virgili donde los investigadores tienen la oportunidad de divulgar su investigación en cada una de las materias descritas anteriormente. Además de la presencia constante en los medios de comunicación ${ }^{48}$, cabe destacar que la Cátedra conforma el punto de encuentro de los diferentes profesionales del sector de la vivienda y de la sociedad. A partir de 2017 se ha dado un paso más en nuestro ímpetu por transferir y se ha participado en eventos como «QQuieres saber qué investigo?» (ComCiència de la URV ${ }^{49}$ ) (sobre agentes inmobiliarios), en el «TEDx Gràcia»

44 «Ir más allá de lo que exista y/o se haya dicho en el debate internacional o, como mínimo, local» (Gurrea Martínez, 2018: 2).

45 Véase < http://housing.urv.cat/es/portada/docencia/posgrado-agente-inmobiliario/> (visitado: 26-042018).

46 Véase <http://housing.urv.cat/es/portada/docencia/postgrau-mediacio/> (visitado: 26-04-2018).

47 Véanse algunas obras de los investigadores de la Cátedra en <http://housing.urv.cat/es/portada/investigacion/publicaciones/> (visitado: 01-08-2018).

48 Vid. supra.

49 Véanse <https://www.youtube.com/watch?v=aqyI-9uig3s> y <https://www.youtube.com/ watch? $v=w M W f d O u H 4 U c>$ (visitados: 26-04-2018). 
de Barcelona ${ }^{50}$ (sobre propiedad compartida y propiedad temporal), en la sesión «Speakeasy $2^{51} »$ (sobre tenencias de la vivienda) y en «Pint of Science ${ }^{52}$ » (sobre sinhogarismo).

Y es a través de la docencia especializada a profesionales y de la transferencia, ambas basadas en la investigación, que se llega al impacto social ${ }^{53}$.

\subsection{El rol de los partners profesionales e internacionales}

El hecho que la Cátedra cuente con 9 partners provenientes tanto de la Administración pública como de colectivos profesionales de ámbito nacional facilita que sus investigadores estén permanentemente al corriente de las necesidades reales en la práctica y los problemas a los que se enfrenta en cada momento el sector de la vivienda en todas sus vertientes. Los partners participan en la preparación y gestión de los proyectos, así como también en la ejecución de estos, en la transferencia de sus resultados, en su diseminación y, ulteriormente, contribuyen a que generen efectivamente un impacto social, económico y/o político-legislativo.

De hecho, desde la Cátedra de Vivienda se alcanza el impacto social, principalmente a través de las dos vías, «a»y «b», propuestas por Lakey et al. (2014: 43), representadas en la figura 4.

Figura 4. Representación esquemática sobre la difusión del impacto.

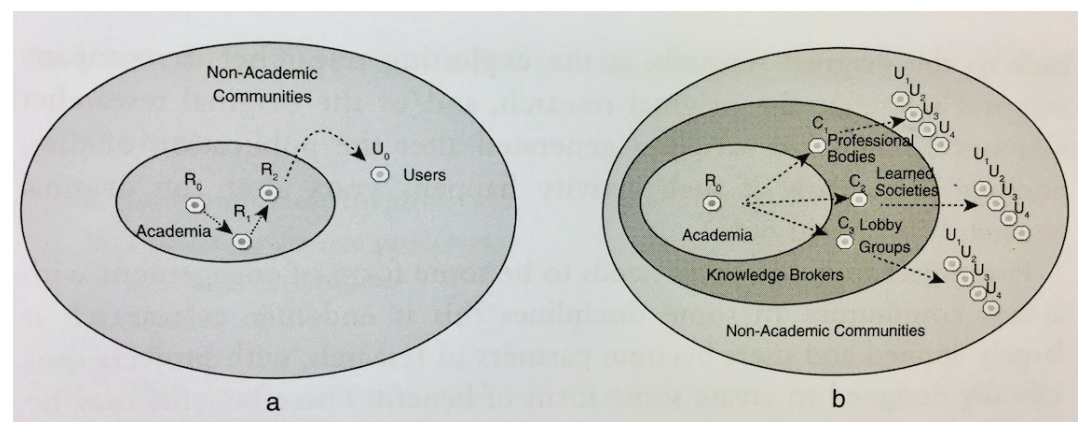

Fuente: Lakey, Rodgers y Scoble (2014: 43).

La vía «a» se da en los casos donde los resultados de la investigación impactan directamente en la sociedad provocando un cambio o una mejora sin la intervención de intermediarios. En el ámbito de la Cátedra de Vivienda de la URV, es el

50 Véase <https://www.youtube.com/watch?v=K7ZTT6Yj0kw> (visitado: 26-04-2018).

51 Véase <http://www.monapart.com/es/magazine/noticias/usos-y-consumos-de-la-vivienda-segunda-edicion-de-speakeasy> (visitado: 26-04-2018).

52 Véase <https://pintofscience.es/event/da-16-pub-highland> (visitado: 26-04-2018).

53 Vid. infra. 
caso, por ejemplo, de asesoramiento en asuntos específicos como, por ejemplo, en el proyecto «Reviure Solanell ${ }^{54}$ », al Ayuntamiento de Valls ${ }^{55}$, a la Fundación Mambré56, a Omplim ${ }^{57}$, a Pandorahub ${ }^{58}$, a iniciativas de arquitectos jóvenes y asociaciones vecinales para utilizar tenencias intermedias para evitar pisos vacíos y gentrificación de barrios, para impulsar la remodelación y reutilización del central edificio del Banco de España de Tarragona ${ }^{59}$, etc.

Esta vía es usualmente la más complicada para conseguir impacto social, dado que en la mayoría de los supuestos resulta necesario contar con la iniciativa de instituciones extraacadémicas que tengan interés en la investigación de la Cátedra. Para ello es necesario que previamente la conozcan y, además, con cierta profundidad para poder valorar ex ante si les resulta útil o interesante para sus necesidades o fines.

Así, la vía que ha permitido a dichas entidades conocer nuestra actividad y los resultados de la investigación ha sido la presencia en los medios de comunicación (ver el impacto supra) y, en menor medida, las redes sociales ${ }^{60}$. Este primer contacto ha venido seguido usualmente de reuniones en la sede de la Cátedra. También las recientes actividades de transferencia han contribuido notablemente a ello, como es el caso, por ejemplo, de Pandorahub y la de los jóvenes arquitectos de Barcelona, que contactaron con la Cátedra gracias al «TEDx Gràcia 2017», mencionado antes.

La vía «b» es la utilizada habitualmente por la Cátedra y en la que nuestros partners desempeñan un rol más relevante, pues actúan como intermediarios proactivos para lograr el impacto social mutuamente deseado. Por ejemplo, los agentes de la propiedad inmobiliaria (representados por el Consejo General de Agentes de la Propiedad Inmobiliaria y el Colegio de Agentes de la Propiedad Inmobiliaria de Tarragona), dada la naturaleza de su profesión, pueden desde su oficio impulsar el uso de las tenencias intermedias (así se forman, por ejemplo, en nuestro curso ho-

54 Se trata de una cooperativa que combina trabajo y vivienda. Véase en: <http://www.reviuresolanell.com $>$ y <http://housing.urv.cat/es/portada/noticias/page/19/> (visitado: 26-04-2018).

55 Véase <https://delcamp.cat/vallsdiari/societat/valls-horitzo-2021-potenciar-lobtencio-dhabitatge-existent-i-buit $>$.

56 Véase <http://housing.urv.cat/participacio-de-diversos-investigadors-de-la-catedra-a-la-jornada-de-formacio-de-la-fundacio-mambre/> (visitado: 27-04-2018).

57 Véase <https://www.omplim.cat $>$ (visitado: 27-04-2018).

58 Véase <http://www.pandorahub.co > (visitado: 27-04-2018).

59 <http://www.diarimes.com/es/noticias/tarragona/2018/04/24/la_remodelacion_del_banco_espana_manos_del_fondo_europeo_feder_38122_1091.html > (visitado: 27-04-2018).

$60 \mathrm{La}$ Cátedra ha sido solo parcialmente exitosa en las redes sociales, contando con un modesto número de seguidores, en 2018, en sus cuentas de Twitter (@housingchairurv, 446), Facebook (<https:// www.facebook.com/housingchairurv/>, 305) y LinkedIn (<https://www.linkedin.com/company/ càtedra-d'habitatge-de-la-urv/>, 111), y en canal de YouTube (<https://www.youtube.com/channel/ UCFTDIqq7QTTKJszbxH14prA?view_as=subscriber $>, 13$ suscriptores). 
mologado de agente inmobiliario); también el mismo Consejo General de Agentes de la Propiedad Inmobiliaria financia parte de una beca predoctoral para identificar los retos de la profesión de la intermediación inmobiliaria; el Ayuntamiento de Reus ha colaborado en la elaboración del documental El Umbral para sensibilizar política y socialmente sobre la problemática el «sinhogarismo»; se ha trabajado con la Agencia de Vivienda de Cataluña para la elaboración de unos criterios sobre un nuevo régimen de arrendamientos urbanos en Cataluña, etc.

La Cátedra procura mantener a los partners al día de los proyectos, necesidades e inquietudes y les invita a participar activamente en sus actividades. De hecho, la Cátedra sirve como punto de encuentro entre la sociedad, los profesionales, la Administración pública, el tercer sector y los emprendedores o empresarios. Para ello, desde la Cátedra se organizan regularmente los mencionados workshops que favorecen la discusión y el intercambio de ideas entre todos los colectivos relacionados con el sector de la vivienda ${ }^{61}$. Así, a través de la Cátedra, los partners reciben la aportación de un conocimiento científico, objetivo e innovador. Por este motivo es habitual que los partners cuenten con los investigadores de la Cátedra como ponentes para impartir conferencias en jornadas y congresos ${ }^{62}$.

Además, los partners también tienen la oportunidad de aportar su visión en la comunidad científica a través de las publicaciones en la revista Housing ${ }^{63}$, así como también de participar en proyectos nacionales e internacionales. Por último, cabe mencionar que algunos partners han facilitado que la Cátedra haya podido colaborar con otras instituciones con las que no tenía contacto directo hasta el momento. Es el caso de Mutua de Propietarios y de su fundación ${ }^{64}$, con los que ha trabajado dos cuestiones que han tenido una importante repercusión ${ }^{65}$ : el impacto de la crisis en las comunidades de propietarios (2017) y la accesibilidad de las personas con discapacidad a sus viviendas en las comunidades de propietarios (2018).

61 Hasta la fecha (26-04-2018) la Cátedra ha organizado 13 workshops interdisciplinares y 7 internacionales. Véase, por ejemplo, el último workshop, celebrado el 10 de abril de 2018, en: <http://housing.urv.cat/celebracio-del-13e-workshop-interdisciplinar-dret-a-lhabitatge-proteccio-internacional-dels-deutors-hipotecaris-i-habitatge-i-ciutadania/> (visitado: 26-04-2018).

62 Por ejemplo, en septiembre de 2018 la Cátedra participó en el congreso Unión Inmobiliaria organizado por el Consejo General de Agentes de la Propiedad Inmobiliaria (<http://housing.urv.cat/es/presencia-dela-catedra-unesco-de-vivienda-en-el-congreso-nacional-de-agentes-de-la-propiedad-inmobiliaria-en-zaragoza-los-dias-28-y-29-de-septiembre-de-2017/>) y en junio de 2016, en el congreso nacional e internacional organizado por el Consejo general de Administradores de Fincas (<http://housing.urv.cat/es/portada/noticias/page/16/>).

63 Ver los 9 números de la revista Housing publicados hasta el momento en: http://housing.urv.cat/es/portada/investigacion/newsletter/ (visitado: 26-07-2018).

64 Véase <https://www.mutuadepropietarios.es/?lang=ca > (visitado: 27-04-2018).

65 Véase el importante impacto mediático de este último estudio en https://gestionline.mutuadepropietarios. es/es/newsletter-agentes-es/839-la-fundacion-mutua-de-propietarios-presenta-el-estudio-la-accesibilidaden-las-viviendas-de-espana-2.html> (visitado: 30-04-2018). 
A nivel internacional, la Cátedra trabaja en red con instituciones como UNESCO, UN HABITAT, ENHR (European Network for Housing Research), la Verband Deutscher Pfandbriefbanken (VdP), el Affordable Housing Hub (ETH Zürich), el centro Property Law, de la Universidad de Cambridge (Reino Unido), y la UIPI (International Union of Property Owners). Este trabajo internacional en red es bidireccional: se aprende de experiencias (de éxito o fracaso) comparadas y también se aportan los resultados de la investigación propia. Aunque técnicamente no son partners de la Cátedra (no gozan estatutariamente de sus mismos derechos y obligaciones), sí que resultan imprescindibles para transferir e impactar socialmente también a nivel europeo e internacional.

La figura 5 muestra estas relaciones de la Cátedra con instituciones en 2018 vinculadas a los temas que habitualmente trabajamos con ellas.

Figura 5. El trabajo en red internacional de la Cátedra en 2018.

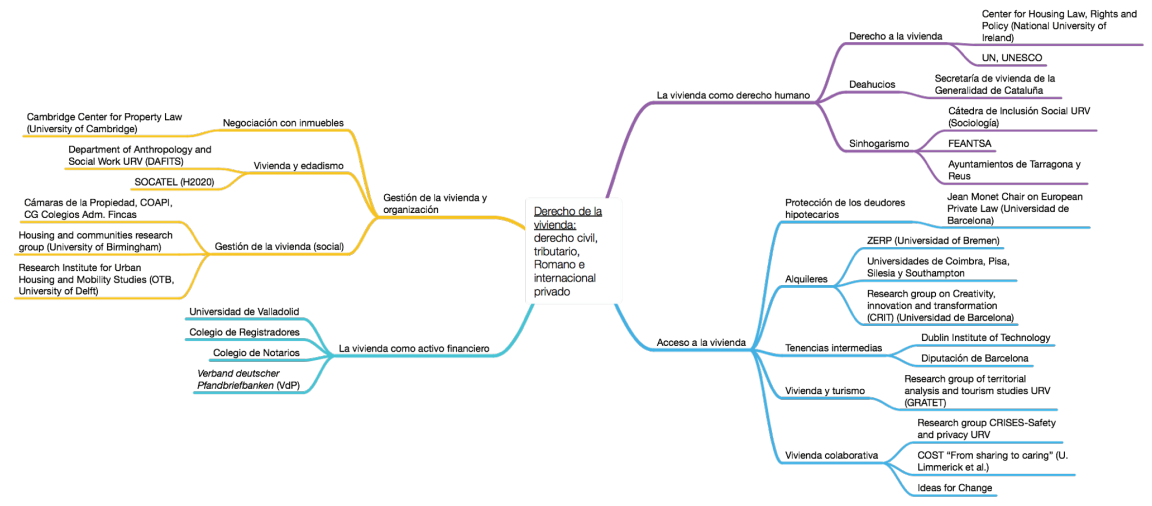

Fuente: elaboración propia.

\subsection{El impacto social de la investigación en vivienda}

\subsubsection{Sobre el impacto social}

No debe confundirse el «impacto social» con el «impacto científico». Mientras este último se refiere al impacto que los resultados de la investigación tienen en el ámbito académico o científico (es decir, intrauniversitario), el impacto social se da cuando los resultados de la investigación se ven reflejados a través de cambios o mejoras en la sociedad, en la economía, en las políticas públicas, en la salud, en el medio ambiente..., o sea, en un ámbito extrauniversitario. Así, el The Arts and Humanities Research Council (AHRC) entiende por «impacto» la «influencia» de la investigación o su «efecto» en un individuo, comunidad o desarrollo de una 
política o la creación de un nuevo producto o servicio. Se relaciona con el efecto de la investigación en la vida económica, social y cultural (Chandler, 2014: 2).

Para alcanzar cierto «impacto social» es necesario que la sociedad esté implicada en la investigación desde el primer momento (carácter ex ante) y no solo una vez finalizado el proyecto, cuando se obtengan las conclusiones o los resultados (carácter ex post). De esta forma, se pueden recibir los feedbacks de la sociedad (a través de los partners, por ejemplo, $\mathrm{u}$ otros grupos de representación) a medida que se va desarrollando el proyecto para que la investigación sea acorde a las necesidades o problemas reales. Un ejemplo de las diferentes formas en que la sociedad puede participar en el desarrollo de la investigación es a través de la participación de stakeholders en jornadas, congresos, seminarios, encuestas, redes sociales..., donde pueda haber una interacción directa entre la sociedad y la comunidad científica ${ }^{66}$.

Tampoco debe confundirse el impacto social con la transferencia de conocimiento (Flecha García, 2015: 50). La transferencia consiste en trasladar la investigación a la sociedad, pero sin que necesariamente implique una mejora o un cambio. Por ejemplo, publicaciones en prensa, impartición de conferencias o ponencias, actividades de divulgación, etc. La docencia en sí tampoco constituye impacto social, sino que más bien es una vía, igual que la transferencia, para poder alcanzarlo, dado que los que la reciben son los operadores que posteriormente aplicarán el conocimiento transmitido.

La importancia de alcanzar impacto social a través de la investigación llevada a cabo en las universidades, especialmente en las públicas, radica básicamente en que la principal fuente de financiación de estas proviene de la sociedad (Grau Vidal, 2015). De manera que esta debe a cambio experimentar un retorno positivo u obtener un beneficio (tanto de los resultados parciales como finales de los proyectos, como del follow up de estos o incluso de los errores ${ }^{67}$ ). De hecho, asílo espera, dado que la universidad pública se situaba en julio de 2011 entre aquellas instituciones y profesionales en los que la sociedad deposita más su confianza después de los científicos y los médicos (Grau Vidal, 2012: 15).

Pues bien, en el ámbito de las ciencias sociales, en concreto, en el ámbito del derecho, Gurrea Martínez $(2018: 11)$ considera que «la academia jurídica puede contribuir, positiva o negativamente, al progreso, la innovación o la competitividad de un país, no solamente por su capacidad para influir en la formación de futuros juristas que aplican el Derecho (abogados, jueces, fiscales, etc.), sino

66 Véase cómo pueden influir los partners externos mientras se lleva a cabo la investigación. En Daley, Rob y Shinton, Sara (2014: 75) y Jackson, Andy (2014: 136).

67 Ver breve resumen del caso de la penicilina en <https://blogs.20minutos.es/ciencia-para-llevarcsic/2015/04/29/la-casualidad-que-llevo-al-descubrimiento-de-la-penicilina/> (visitado: 25-04-2018). 
también por la posibilidad de influir, de manera directa o indirecta, en el proceso legislativo. Por lo tanto, una academia sofisticada y moderna que conozca el debate internacional y las contribuciones de otras disciplinas no sólo garantizará la calidad en una determinada jurisdicción, sino que también promoverá la generación de ideas y propuestas de reforma legislativa que promuevan el crecimiento y la innovación». Con ello la Cátedra está totalmente de acuerdo y así lo ha llevado a cabo en diversas ocasiones, como verán a continuación.

Según Chubb (2014: 22) existen veinte razones que motivan realizar investigación que alcance un impacto social ${ }^{68}$, que van desde el amor por lo que uno hace a hacer carrera académica. Para la Cátedra resulta complicado escoger cuál de entre todas ellas nos motiva a investigar, transferir y querer impactar en materia de vivienda; quizá una combinación de algunas de ellas. Pero si se tuviese que definir en una frase la razón para llevar a cabo así nuestro trabajo sería «favorecer el acceso a la vivienda de las personas y evitar su pérdida».

\subsubsection{Nuestro impacto social hasta el momento}

Favorecer la efectividad del derecho a la vivienda digna y adecuada está previsto en la Constitución (arts. 10 y 47), en el Estatuto de Autonomía de Cataluña (art. 26), y en el Plan Estatal de Vivienda (2013-2017), es Pilar Social de la UE desde $2017^{69}$ y lo acoge la Agenda Urbana Habitat III 2016 de la ONU ${ }^{70}$, donde se marca la línea de actuación para las ciudades a nivel mundial para los próximos veinte años.

En este marco, la Cátedra quiere y busca que su investigación impacte en la sociedad, provocando en ella alguna mejora. Así, como se ha dicho, el impacto social de la línea de investigación en vivienda se podría resumir en que persigue facilitar el acceso a la vivienda de las familias y evitar su pérdida. Es decir, esta es la finalidad última del conjunto de las actividades realizadas en la Cátedra (investigación, transferencia y docencia), como rediseñar y legislar sobre formas de tenencia de la vivienda en conjunción con diversos derechos humanos como la vivienda o la propiedad o analizar a nivel internacional y posteriormente asesorar

68 Son: marcar la diferencia, estatus, curiosidad, aumentar el conocimiento, crear nuevas ideas, influenciar en políticas y en la práctica, realizar cambios u ofrecer evidencias, crear nuevos servicios, amor y pasión por el trabajo o la materia que se investiga, progresar en la carrera académica, responder preguntas y plantear nuevas, encontrar nuevas maneras de hacer las cosas, provocar un efecto, contribuir al bienestar social, atraer al público, crear nuevos productos, hacer descubrimientos, ser el primero, el mejor o el experto, poder hacer consultas y la libertad académica.

69 Véase en: <http://www.europarl.europa.eu/sides/getDoc.do?pubRef=-//EP//TEXT+TA+P8-TA2017-0010+0+DOC+XML+V0//EN> (visitado: 27-04-2018).

70 Véase en: <http://habitat3.org/wp-content/uploads/NUA-Spanish.pdf> (visitado: 27-04-2018). 
localmente sobre políticas de prevención, tratamiento y reacción a los desahucios y el sinhogarismo.

Para ello, el impacto a alcanzar debe ser multinivel y «glocal». Es decir, debe tener diversos ámbitos geográficos, desde el local al internacional (global); pero, además, dichos ámbitos no son compartimentos estancos, sino que interaccionan e impactan entre sí, contribuyendo al fenómeno conocido como «glocalización» (glocalisation) (Grau Vidal, 2014: 2). Es importante tener en cuenta el aspecto territorial de la Cátedra de Vivienda de la URV, puesto que la condiciona, al tener esta su sede en una universidad joven, con el campus disperso entre diversos municipios de tamaño medio o pequeño, la cual sufre a menudo, al igual que la ciudad de Tarragona y su provincia, el fenómeno conocido como «Barceluña» (Barcelona como polo de atracción de todo lo que sucede; otro ejemplo de la carencia de cohesión territorial en nuestro país).

De este modo, los niveles de nuestro impacto social son:

a) Ámbito internacional. La UNESCO y la ONU (Uni Habitat) han contado con la Cátedra para implementar la Nueva Agenda Urbana 2016, debido al know-how acumulado de esta en llevar la investigación a la realidad legislativa y de políticas de vivienda. Con ellas se han llegado a firmar acuerdos que posibilitan, de momento, participar a nivel autonómico (Cataluña ${ }^{71}$ y local (Tarragona) para implementarla efectivamente.

b) Ámbito UE. Investigadores de la Cátedra asesoran al Parlamento Europeo en la problemática de las transacciones inmobiliarias transnacionales ${ }^{72}$ y también a la Comisión Europea en materia del mercado hipotecario ${ }^{73}$.

c) Ámbito estatal. La Cátedra ha participado en la elaboración de la Ley 4/2013 (LAU) y en el Plan Estatal de Vivienda 2013-201774. También hay que destacar la colaboración con iniciativas profesionales, como The Hound ${ }^{75}$, el proyecto Solanell ${ }^{16}$ o Pandorahub ${ }^{77}$.

d) Ámbito catalán. Se ha impulsado y contribuido a la elaboración de la Ley 20/2014 (protección de consumidores hipotecarios) y la Ley 19/2015 (tenencias intermedias: propiedad temporal y propiedad compartida), además de deponer

\footnotetext{
71 Véase <http://premsa.gencat.cat/pres_fsvp/AppJava/notapremsavw/299954/ca/govern-inicia-lelaboracio-lagenda-urbana-catalana-orientar-desenvolupament-sostenible-ciutats.do > (visitado: 26-04-2018).

72 Véase <http://www.europarl.europa.eu/RegData/etudes/STUD/2016/556936/IPOL_STU(2016)556936_ EN.pdf $>$.

73 Véase <https://ec.europa.eu/info/finance-events-160201-covered-bonds_en> (visitado: 26-04-2018).

74 Véase <http://www.urv.cat/ca/universitat/coneixeu/persones/professorat-destacar/52/sergio-nasarre > (visitado: 26-04-2018).

75 Véase <https://blogthehound.wordpress.com> (visitado: 26-04-2018).

76 Vid. supra.

77 Vid. supra.
} 
en diversas ocasiones en el Parlamento de Cataluña en relación con otras reformas legislativas.

e) Ámbito local. Se ha participado en la delimitación de los objetivos y puesta en práctica de planes de actuación tanto de Ayuntamientos (sinhogarismo ${ }^{78}$ ) como de diputaciones provinciales (masovería urbana ${ }^{79}$ ).

A pesar de tener feedbacks informales de que la transferencia de conocimientos en forma de leyes y por otras vías ayuda a mejorar la vida de las personas en su acceso a la vivienda, hoy en día la Cátedra carece de unos indicadores claros y de una sistemática que nos posibilite conocer exactamente cuántos o con qué intensidad se ha logrado o cuáles han sido en concreto las situaciones mejoradas.

Lo que sí se tienen son algunos indicios algo más formales de que estamos produciendo cambios relevantes en nuestro ámbito a nivel social. Por ejemplo:

- Se ha contribuido a impulsar y diseñar cuatro leyes y decretos de vivienda (tanto a nivel estatal como autonómico), pudiendo impactar en 47 millones de personas y 25 millones de viviendas. Al plasmarse la investigación usualmente en leyes civiles:

- El impacto es sostenible, pues no tienen coste económico directo para la Administración pública, por ejemplo, en forma de subsidios, imposición de sanciones, compensación por expropiaciones, etc., que suelen ser las aproximaciones tradicionales a la vivienda desde el derecho público.

- Los derechos son tangibles y exigibles, no quedando en difusos principios generales y valores, a menudo difícilmente concretables o aplicables directamente.

- Y su contenido es más estable y no está tan sujeto como las normas de derecho público a los vaivenes del color político de los Gobiernos multinivel de turno ${ }^{80}$.

- El TC ha confirmado la constitucionalidad de la propiedad temporal (sentencia del TC de 6 de julio de 2017 ${ }^{81}$ ), destacando expresamente dicho Tribunal que «constituye, sin embargo, una actualización de las

78 Véase <https://www.tarragona.cat/serveis-a-la-persona/noticies/serveis-a-les-persones/12019ajuntamentimpulsa-un-pla-d2019accio-per-abordar-el-sensellarisme-1> (visitado: 26-04-2018).

79 Véase <http://www1.diba.cat/llibreria/lstDetall_Publicacions.asp?Opener=Libreria\&ID=57962> (visitado: 26-04-2018).

80 Piénsese que nuestro Código Civil vigente es de 1889 y ha sufrido cambios muy concretos en todos estos años; y nuestros fundamentos de derecho hipotecario vigentes se aprobaron ya en la Ley Hipotecaria de 1861. En cualquier caso, los pilares de nuestro derecho privado vigente tienen más de 2.000 años de antigüedad.

81 RTC $2017 \backslash 95$ (BOE núm. 191 de 11 de agosto de 2017). La propiedad compartida nunca fue impugnada, de manera que su constitucionalidad y compatibilidad con el concepto tradicional de la propiedad fueron admitidas desde el primer día de la vigencia de la Ley 19/2015. 
necesidades presentes de acceso a la vivienda de un principio preexistente en dicho ordenamiento, cual es la utilización de fórmulas de dominio dividido para facilitar el acceso a la propiedad».

- La investigación llevada a cabo ha obtenido una buena evaluación del SIOR del impacto social del proyecto europeo TENLAW sobre arrendamientos urbanos en el que participamos y lideramos el equipo para España, Portugal y Malta ${ }^{82}$.

- La Cátedra ha sido invitada a participar en la elaboración e implementación de la Nueva Agenda Urbana de la ONU en Cataluña ${ }^{83}$.

La figura 6 muestra con más detalle aquellos indicios del impacto social alcanzado por la Cátedra UNESCO de Vivienda hasta hoy.

Figura 6. El impacto social de nuestra investigación en materia de vivienda.

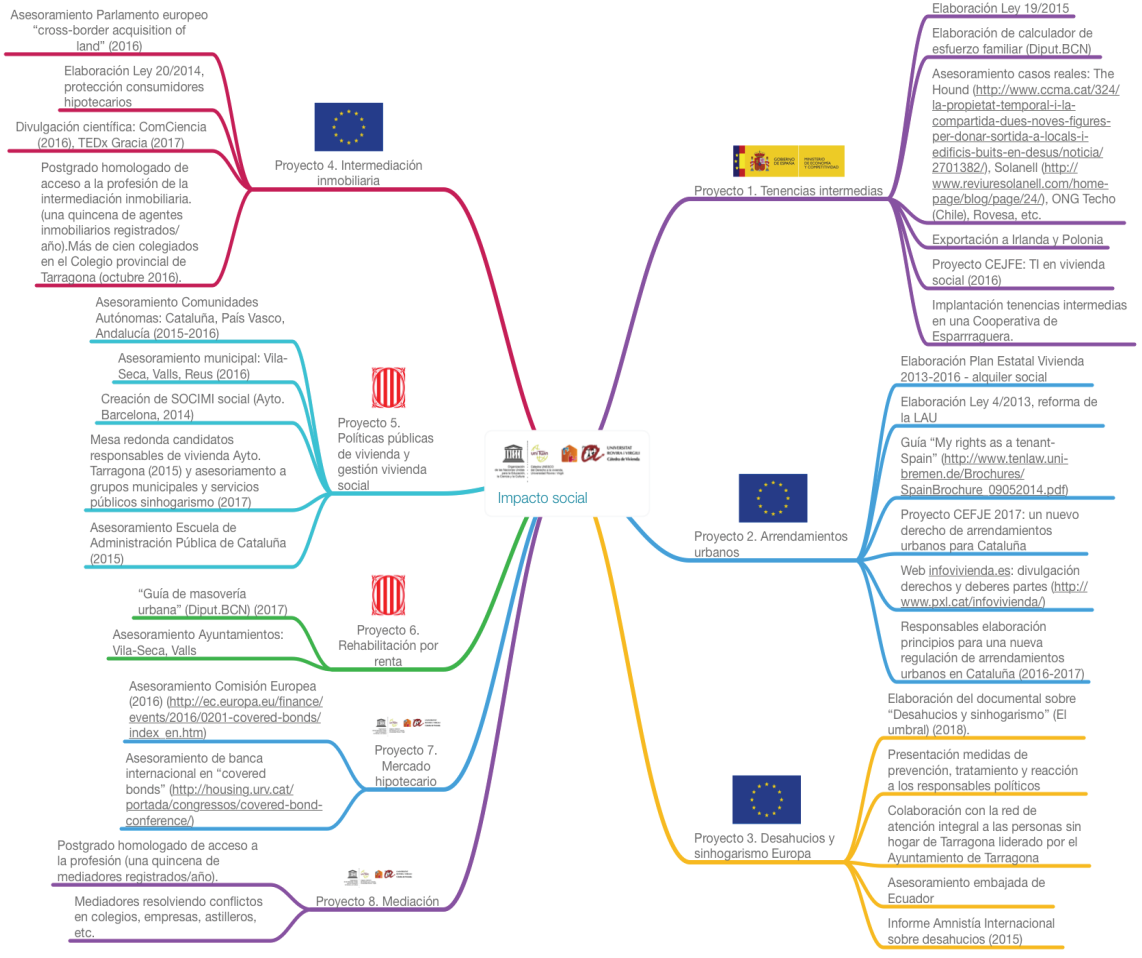

Fuente: elaboración propia.

82 Véase http://sior.ub.edu/jspui/cris/project/pj00058/pjinfo.html (visitado: 01-08-2018). De conformidad con este repositorio, el impacto social alcanzado a través del proyecto «TENLAW» es el siguiente: mejora de las condiciones de vivienda reduciendo el riesgo de pobreza, proporcionar una oportunidad más eficiente para la investigación internacional e interdisciplinaria en el campo de la vivienda y la propiedad, mejora de las medidas de flexibilización y promoción del mercado de alquiler.

83 <http://territori.gencat.cat/es/detalls/Article/agenda_urbana> (visitado: 30-04-2018). 
A continuación, se toman como ejemplo tres de los proyectos llevados a cabo en la Cátedra donde se percibe que se ha alcanzado un impacto social para analizar el iter o la cadena de valor que se ha seguido para lograrlo. Son:

1. Tenencias intermedias. El problema a resolver era la imposibilidad de las clases medias y bajas para acceder a una vivienda estable en propiedad sin sobreendeudarse (causa fundamental de la burbuja inmobiliaria y de su crash en 2007). La solución resultante de la investigación fue la creación de dos tenencias intermedias (la propiedad compartida y la temporal ${ }^{84}$ ) desconocidas desde Napoleón ${ }^{85}$. Las evidencias de impacto social hasta el momento son la elaboración de la Ley 19/2015 (que facilita el acceso a los 3,8 millones de viviendas en Cataluña - y a otros bienes inmuebles $y$ muebles identificables - de manera estable, flexible y evitando el sobreendeudamiento familiar al acceder a través de una de esas dos formas ${ }^{86}$ ) y que, actualmente, se está elaborando un «calculador de esfuerzo familiar» junto con la Diputación de Barcelona para ayudar a las personas y profesionales a elegir la mejor forma de tenencia de la vivienda. Uno de sus primeros usos reales fue para comprar y poner en marcha una ferretería ${ }^{87}$. También se han exportado a Irlanda y Polonia a través de investigadores visitantes a la Cátedra.

2. Alquileres. Gracias al proyecto europeo TENLAW ${ }^{88}$ se estudió por qué los alquileres funcionan en unos países y en otros no, como es el caso de España. La conclusión que se extrajo es que los alquileres se debían regular como una alternativa real a la propiedad, para evitar futuras burbujas inmobiliarias, y no como una mera tenencia residual. Algunas evidencias de impacto social que se derivan de los estudios realizados en arrendamientos son que en 2013 contribuimos a la reforma de la Ley de Arrendamientos estatal (LAU), teniendo una potencial aplicación en las 25 millones de viviendas que hay en España y que en 2017 se diseñó un marco más avanzado y europeizado para Cataluña ${ }^{89}$, que fue asumido en

84 Véanse <http://housing.urv.cat/es/portada/investigacion/proyectos/tenencias-intermedias2/> y <https:// www.youtube.com/watch?time_continue $=5 \& \mathrm{v}=\mathrm{KChoy} 2 \mathrm{eV0Oo}>$ (visitados: 26-04-2018)

85 Refiriéndose al Código Civil francés o llamado Código de Napoleón de 1804, donde se reconoció el derecho a la propiedad privada de forma absoluta — sin posibilidad de fraccionarla—, que influyó en la elaboración del Código Civil español de 1889.

86 Véase <http://diaridigital.urv.cat/sergio-nasarre-compareix-avui-al-parlament-de-catalunya-per-parlarsobre-habitatge/> (visitado: 30-04-2018).

87 Véase vídeo de TV3: <http://www.ccma.cat/324/la-propietat-temporal-i-la-compartida-dues-noves-figures-per-donar-sortida-a-locals-i-edificis-buits-en-desus/noticia/2701382/> (visitado: 30-04-2018).

88 Véase <http://www.tenlaw.uni-bremen.de> (visitado: 26-04-2018).

89 <http://www.lavanguardia.com/vida/20160927/41611060317/sergio-nasarre-alquiler-catedra-habitatge-urv.html > (visitado 30-04-2018). 
su inmensa mayoría por la Generalitat de Cataluña, sobre el que se quiere redactar un proyecto de ley en 2018. También se ha diseñado y publicado la web Infoviviend $\mathrm{a}^{90}$, que resuelve dudas de propietarios, profesionales e inquilinos, la cual ya registra varios centenares de visitas.

3. Desahucios y sinhogarismo ${ }^{91}$. El problema a tratar en este proyecto era determinar la cifra de desahucios en Europa y cuántas de las familias afectadas acababan sin hogar, y correlacionarlo con las políticas nacionales y normas de prevención, tratamiento y reacción a estos fenómenos. Se recogieron y analizaron, en consecuencia, las medidas adoptadas en cada uno de los 28 Estados miembros. A resultas de este proyecto, la Cátedra ha producido la elaboración de un documental (El Umbral ${ }^{92}$ ) que busca concienciar a los responsables políticos y a la sociedad en general sobre la problemática de los sinhogar, así como también está colaborando con los ayuntamientos de Tarragona y Reus y con el Gobierno de Cataluña para elaborar planes contra el sinhogarismo ${ }^{93}$. Además, en 2018 se ha elaborado profesionalmente una experiencia de simulación para que los jóvenes puedan concienciarse sobre esta realidad ${ }^{94}$.

La figura 7 esquematiza la cadena de valor hasta el impacto social en estos tres proyectos mencionados.

90 Véase <http://infovivienda.es> (visitado: 26-04-2018).

91 Véase el estudio en: <http://ec.europa.eu/social/main.jpp?catId=738\&langId=en\&pubId=7892\&type=2 $\&$ furtherPubs $=y e s>$ (visitado: 26-04-2018).

92 <http://catalanfilms.cat/es/producciones/El-umbral> (visitado: 26-04-2018).

93 <http://premsa.gencat.cat/pres_fsvp/AppJava/notapremsavw/302251/ca/lestrategia-integral-labordatge-sensellarisme-catalunya-impulsada-pel-govern-presenta-treballs-model-catala-llar-housing-first.do > (visitado: 30-04-2018).

94 Véase <http://housing.urv.cat/es/experiencia-el-llindar/> (visitado: 01-08-2018). Véase también la noticia de prensa: <https://www.diaridetarragona.com/tarragona/Preguntan-a-alumnos-de-Tarragona-Y-si-elsintecho-fueras-tu-20180612-0090.html> (visitado: 25-07-2018). 


\section{Figura 7. Tres ejemplos sobre el iter seguido por la Cátedra UNESCO de Vivienda para alcanzar impacto social.}

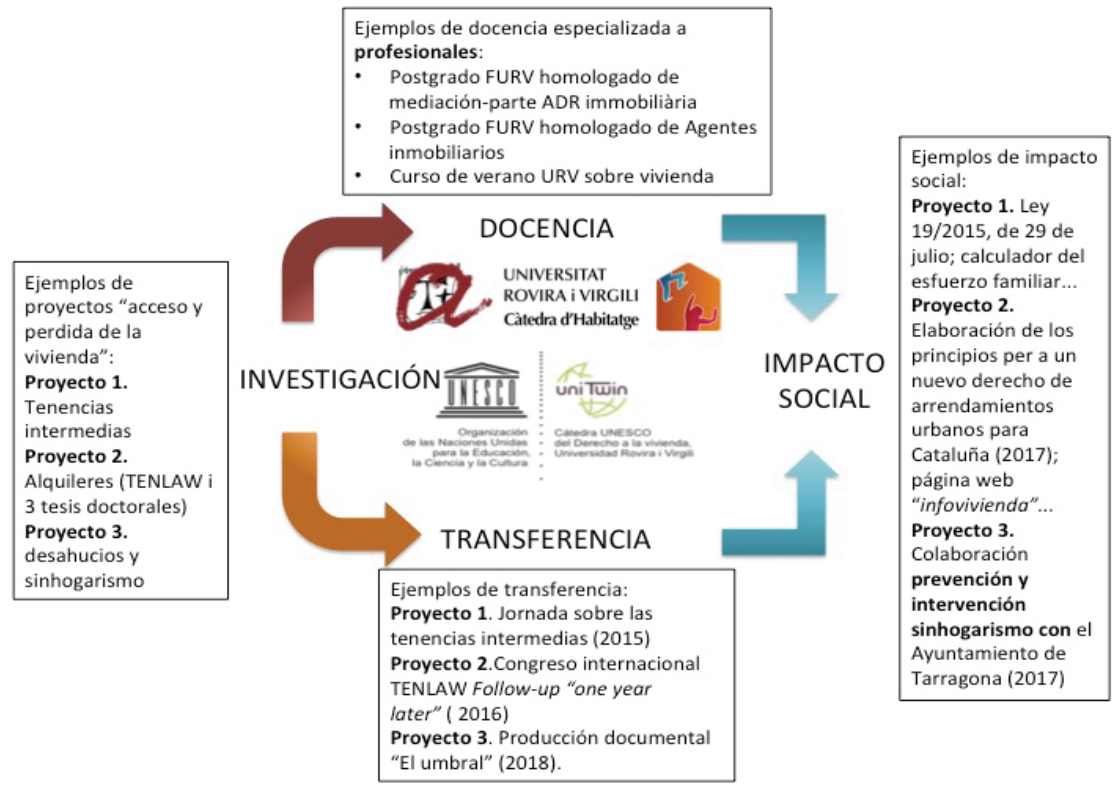

Fuente: elaboración propia.

\subsubsection{Retos en el impacto social de la investigación en vivienda}

Evidentemente, esto no es suficiente. Se han identificado algunos elementos que pueden ayudar a incrementar el impacto social de la investigación ${ }^{95}$ en materia de vivienda:

1. Necesidad de que haya una formación académica en materia de vivienda. Resulta necesaria la existencia de un grado universitario (Grado de Vivienda, dado que las competencias a adquirir son de nivel de grado y no de posgrado) de carácter interdisciplinar (economía, empresa, derecho, arquitectura, sociología, etc.) con contenidos de ámbito nacional e internacional, que pueda formar a los miles de profesionales de este sector que tradicionalmente no han tenido opción a una formación universitaria ad hoc, como son los agentes inmobiliarios, los administradores de fincas, trabajadores de notarías, registros de la propiedad, de Administraciones

95 Como se ha visto en este trabajo, es muy prolija, tanto en temas como en producción. Además, en 2018, Tirant lo Blanch, la editorial jurídica española más prestigiosa según el índice SPI vigente (<http://ilia.cchs. csic.es/SPI/buscar_editoriales.php?editorial=Tirant+Lo+Blanch $>$, visitado: 01-08-2018), nos ha encargado la dirección de su nueva colección «Derecho de la vivienda», lo que representa un nuevo reto en sí mismo (<https://www.tirant.com/editorial/colecciones/derecho-de-la-vivienda >; visitado: 02-08-2018). 
públicas, etc., relacionados con el sector de la vivienda. Los que se formen en este sector son los que después serán los operadores y los que más pueden impactar en el mismo (gatekeepers), evitando con sus conocimientos la generación de nuevas burbujas y crisis inmobiliarias y garantizando los derechos de los consumidores.

2. Cuantificar y evaluar el impacto social real. Es necesario identificar con más precisión, cuantificar y evaluar cualitativamente los casos efectivos de impacto social. Para ello, pueden utilizarse estas dos vías. La primera es a través de la realización de encuestas entre los colectivos específicos para comprobar si se están implementando los resultados o propuestas realizadas de la Cátedra (por ejemplo, a las Administraciones públicas, a los profesionales, etc.). La segunda es a través de un sistema de big data que permita contabilizar las familias que se han beneficiado de las medidas de cambio o de mejora transferidas. Por ejemplo, ¿cuántos conflictos entre propietarios e inquilinos se resolverán gracias a nuestra web Infovivienda? ¿Cuántas personas evitarán el sobreendeudamiento a través del «calculador de esfuerzo familiar» o de la utilización de las tenencias intermedias en lugar de la propiedad clásica o de un alquiler? ¿En qué medida el documental El Umbral impactará en las políticas de sinhogarismo, por ejemplo, mediante la creación de planes contra el sinhogarismo, dotando más estas políticas o iniciando nuevas?

3. Concienciación sobre la importancia de alcanzar impacto social con la investigación. Se trata de promover que la política de $\mathrm{I}+\mathrm{D}$ tanto nacional como internacional, el colectivo académico en general y, especialmente, los investigadores más jóvenes que liderarán la universidad en el futuro tomen consciencia ( $y$ actúen en consecuencia) sobre la necesidad de que la investigación (al menos la dotada con fondos públicos) tenga impacto social y que los resultados de la investigación no se queden únicamente sobre las estanterías de las bibliotecas o en las revistas especializadas, sino que encuentren una aplicación real y efectiva en la sociedad, todo ello conforme el art. 27 DUDH. 


\section{Conclusiones}

De este trabajo podemos extraer las siguientes conclusiones:

1. La Cátedra UNESCO de Vivienda de la URV nació como un instrumento para cubrir la necesidad de superar las rigideces de un sistema universitario que no favorece una investigación y una docencia interdisciplinares e internacionales con suficiente masa crítica (y especialmente en el ámbito del derecho, donde tradicionalmente ha sido y usualmente es estanca, nacional e individual), donde la transferencia de conocimientos a los profesionales, responsables políticos y la ciudadanía en general pueda desempeñar el rol que se merece y persiga un impacto social real y efectivo. La combinación de este factor con el respaldo estatutario, la confianza del gobierno de la universidad, la existencia de casi una decena de partners profesionales interesados y la participación de diversas investigadoras noveles muy motivadas facilitaron su creación.

2. La Cátedra fundamenta su investigación en cuatro pilares (vivienda como derecho humano, acceso a la vivienda, gestión y organización de la vivienda y la vivienda como activo financiero), y genera docencia y transferencia especializadas (no solo a través de las tradicionales conferencias y congresos, sino también a través de nuevos formatos como, por ejemplo, el «TEDx» o el «Pint Of Science»), las cuales a su vez generan impacto social. El desarrollo y especialización de su estructura ha venido motivado por la asunción de desarrollar más de 20 proyectos de investigación y de centenares de artículos publicados y de conferencias impartidas desde 2013.

3. La motivación de la Cátedra para llevar a cabo impacto social es «favorecer el acceso a la vivienda de las personas y evitar su pérdida». Para conseguirlo, se utilizan tanto la vía directa de los stakeholders (especialmente, a través de la difusión de los resultados de la investigación a través de los medios de comunicación y en menor medida a través de los medios sociales) como los partners, que, con su implicación desde la gestación de los proyectos, en la comisión de seguimiento, en la revista y en las actividades de docencia y transferencia, están al corriente de lo que podemos ofrecer y generamos y son nuestro puente con la sociedad. Para poder conseguir un impacto multinivel o «glocal», la Cátedra cuenta también con colaboradores estables a nivel internacional.

4. Aunque es difícil cuantificar el impacto social realmente generado hasta el momento y aun sin contar con las herramientas y competencias nece- 
sarias, se tienen algunos indicios que evidencian, en cierta medida, que la Cátedra ha conseguido impacto social, especialmente mediante el diseño e implementación legislativa de nuevas formas de propiedad de la vivienda (las tenencias intermedias de la propiedad compartida y la propiedad temporal), la reformulación de los arrendamientos urbanos partiendo de un proyecto europeo y en el ámbito de nuestros trabajos sobre los desahucios y el sinhogarismo.

5. Todo ello lleva a la Cátedra a seguir insistiendo en que el trabajo de investigación interdisciplinar, docencia especializada y transferencia consigan un mayor impacto social, habiendo evidenciado la necesidad de que exista una formación académica interdisciplinar de grado dedicada a la vivienda (Grado de Vivienda) y la necesidad de dotar a la Cátedra de los mecanismos y herramientas necesarios para cuantificar, evaluar y mejorar nuestro impacto social, al tiempo que sigue siendo necesario generar una mayor concienciación en la política de investigación y universitaria sobre la importancia de alcanzar un impacto social tangible con la investigación, de acuerdo con el art. 27 DUDH. 


\section{Bibliografía}

Chandler, Colin (2014). En Denicolo, Pam (2014). Achieving impact in research. Sage.

Снuвb, Jennifer (2014). En Denicolo, Pam (2014). Achieving impact in research. Sage.

Daley, Rob y Shinton, Sara (2014). En Denicolo, Pam (2014). Achieving impact in research. Sage.

Flecha García, Ramon (2015). «Evaluación del impacto de la investigación en Ciencias Sociales y Humanidades en la Unión Europea. El proyecto IMPACT-EV». Panorama Social, ISSN 1699-6852, n. ${ }^{\circ} 21$, pp. 65-74.

Grau Vidal, Francesc Xavier (2014). La universitat «glocal». GUNi Network.

- (2015). Rànquings, impacte científic i sistemes universitaris. Conferència de rectors de les universitats espanyoles, CRUE Universidades Españolas.

- (2012). La universidad Pública española. Retos y prioridades en el marco de la crisis del primer decenio del siglo XXI. Publicacions URV.

Gurrea Martínez, Aurelio (2018). La sociedad por acciones simplificada como paradigma de innovación jurídica: Una reflexión a propósito de la función social de los investigadores de Derecho a partir de la SAS colombiana. Working Paper Series 2/2018, Instituto Iberoamericano de Derecho y Finanzas (IIDF).

Jackson, Andy (2014). En Denicolo, Pam (2014). Achieving impact in research. Sage.

Lakey, Joe; Rodgers, Geoff y Scoble, Rosa (2014). En Denicolo, Pam (2014). Achieving impact in research. Sage.

Nasarre Aznar, Sergio (2014). «A legal perspective of the origin and the globalization of the current financial crisis and the resulting reforms in Spain». En Kenna, Padraick (ed.) (2014). Contemporary Housing Issues in a Globalized World. Surrey: Ashgate Publishing.

- (2017). Cuestionando algunos mitos del acceso a la vivienda en España, en perspectiva europea. Ediciones Complutense, Cuadernos de Relaciones Laborales, 35/1.

Payne-Gifford, Sophie (2014). En Denicolo, Pam (2014). Achieving impact in research. Sage.

Sánchez Barrilao, Juan Francisco (2017). «Los fundamentos del «progreso informático» en la Unión Europea». UNED. Revista de Derecho Politico, 347, n. ${ }^{\circ}$ 98, enero-abril 2017.

Viglizzo, Ernesto Francisco (2001). La Trampa de Malthus. Buenos Aires: Eudeba. 